\title{
Optimization, Application, and Interpretation of Lactate Dehydrogenase Measurements in Microwell Determination of Cell Number and Toxicity
}

\author{
Hubert Th. Wolterbeek and Astrid J.G.M. van der Meer
}

\begin{abstract}
The lactate dehydrogenase (LDH) assay was addressed for its sensitivity, disturbances by foaming, and cell number and size. Cells were from a U-251 MG grade IV human glioblastoma brain tumor cell line used in $100-\mu 1$ well volumes. Cells were counted by microscopy and Coulter counting; assays were LDH or trypan blue. The results indicate increased $490 \mathrm{~nm}$ signals (level, variance) by using phenol red or by increasing fetal bovine serum from $5 \%$ to $10 \%$. The data also indicate that defoaming results in reduced variances ranging from a factor of 2 at $1-3$ units of absorption, up to a factor of $4-5$ at $<1$ units of absorption. Coulter counting indicated a decrease in cell volume with increasing end-point cell density, attributed to general shrinking at increasing density. In comparisons, total LDH was considered relative to both cell total volume and cell numbers. The result suggests that total LDH should be regarded as reflecting cell total volume rather than cell numbers. In a comparative $\mathrm{Cu}$ exposure test, signals of both LDH and a sodium salt of 4-[3-(4-iodophenyl)-2-(4-nitrophenyl)-2H-5-tetrazolio]-1,3-benzene disulfonate (WST-1) decreased with increasing $\mathrm{Cu}$ supply, while bromodeoxyuridine signals remained largely unaffected. The data show the differences in responses in cell viability and proliferation, but, above all, indicate that LDH should be expressed on a per cell volume basis rather than per cell, to avoid the problem that mere density effects contribute to signals on compound or metal toxicity.
\end{abstract}

\section{Introduction}

$\mathbf{T}$ HE USE OF CELL-BASED ASSAYS by pharmaceutical companies for high-throughput screening of chemical cytotoxicity has increased steadily over recent years. ${ }^{1}$ There are numerous ways to determine viability and numbers of cells in in vitro experimental treatments, ${ }^{2}$ some of which are more suited for larger numbers of cells, for adherent rather than suspended cells, and for clumps of cells, and some of which are more sensitive than others. Although used extensively as convenient and rapid measures, all assays have their disadvantages and must be used with caution. ${ }^{3}$ One of the approaches to assess cell numbers and viability (cell death) is by determining endogenous LDH activities of the cells ${ }^{2,4}$ : the method essentially uses released LDH to mark damaged/dead cells with compromised membranes ${ }^{1,2}$ and total intracellular LDH (after forced cell lysis ${ }^{2,4}$ ) to assess the total number of cells (dead or alive).

However, in $\mathrm{LDH}$ counting, as in all assays, a variety of influences should be considered ${ }^{4}$ : the background LDH content of the serum in a culture medium may vary ${ }^{2}$; phenol red, a pH-sensitive dye often used in media, also absorbs at the LDH $490 \mathrm{~nm}$ line; the linear range of the LDH molar absorbance is known to be limited; LDH signals per cell may depend on cell size ${ }^{2}$; and LDH signals

Department of Radiation, Radionuclides, and Reactors, Faculty of Applied Sciences, University of Technology Delft, Delft, The Netherlands.

ABBREVIATIONS: BrdU, bromodeoxyuridine; FBS, fetal bovine serum; LDH, lactate dehydrogenase; $\mathrm{LDH}_{\mathrm{TOT}}$, total lactate dehydrogenase; MEM, Minimum Essential Medium Eagle; $R_{\mathrm{V}}$ and $R_{\mathrm{NR}}$, total lactate dehydrogenase/cell total volume and total lactate dehydrogenase/cell numbers, respectively; WST-1, sodium salt of 4-[4-(4-iodophenyl)-2-(4-nitrophenyl)-2H-5-tetrazolio]-1,3-benzene disulfonate. 
may be severely disturbed by foam formation ${ }^{2}$ since optical density reading is reported as showing serious errors by bubbles in the wells. ${ }^{5}$

The present paper re-addresses the microwell LDH assay in aspects such as (background) absorbance, linearity, sensitivity, disturbances by foaming, and cell number and size, all meant to track its feasibility and optimize LDH assay functionality in microwell trials over a range of cell densities.

\section{Materials and Methods}

\section{Cell line}

The cell line used in the present study was U-251 MG grade IV human glioblastoma (adherent), a human brain tumor cell line, originating from the Russian Academy of Sciences (St. Petersburg, Russia) and obtained as a gift from the Free University Medical Center, Amsterdam, The Netherlands.

\section{Preculture and experimental media}

Cells were precultured in flasks in MEM, with $2 \mathrm{mM}$ L-glutamine, Earle's Balanced Salt Solution, penicillin/ streptomycin, $1.5 \mathrm{~g} / \mathrm{L}$ sodium bicarbonate, $1 \mathrm{~m} M$ sodium pyruvate, and $0.1 \mathrm{~m} M$ non-essential amino acids with $10 \%$ FBS, without phenol red (Sigma, St. Louis, MO). In experiments/assays, the medium was MEM with 5\% FBS. Preculture and experimental conditions were 5\% $\mathrm{CO}_{2}$ at $37^{\circ} \mathrm{C}$ (Hera Cell Incubator, Haraeus, Hanau, Germany).

\section{Experiments}

For experiments, $100 \mu \mathrm{l}$ of cell suspension (per well) was seeded into wells of a 96-well cell culture plate (96well plates; Costar, Cambridge, MA). FBS content was varied from $5 \%$ to $10 \%$. Starting cell densities were set in triplicate, ranging from 250 cells per well up to $1.7 \times$ $10^{5}$ cells per well. After $24 \mathrm{~h}$, media were removed, and cultures were refreshed by adding $200 \mu \mathrm{l}$ of MEM containing 5\% FBS. Cells were grown for an additional 4 days. In an additional series of 4-day experiments, 5\% FBS-containing media were supplemented with copper in $\mathrm{CuCl}_{2}$ form, added in a concentration range of 2 $\mu \mathrm{mol} / \mathrm{L}$ to $2 \mathrm{mmol} / \mathrm{L}$. In these experiments, cells were invariably seeded at a density of $2 \times 10^{4}$ cells per well.

\section{LDH assays for assessment of cell numbers and viability}

General. LDH was determined using a LDH detection kit (Roche Diagnostics GmbH, Mannheim, Germany); this kit determines LDH activity in enzymatic testing, which involves reduction of $\mathrm{NAD}^{+}$, conversion of lactate to pyruvate, and the ultimate reduction of the tetrazolium salt 2-p-iodophenyl-3-p-nitrophenyl-5-phenyl tetrazolium chloride (INT) to formazan. The formed formazan shows a broad absorption maximum at about $500 \mathrm{~nm}$.

Linearity. To test absorption linearity (at $490 \mathrm{~nm}$ ) against LDH activity, a batch of cells was lysed completely, after which a range of LDH activities was generated in the centrifuged medium by diluting up to a factor of 650 in MEM containing 5\% FBS.

LDH leakage. After incubation, plates were centrifuged for $10 \mathrm{~min}$ at $250 \mathrm{~g}$ (model B 3.11 table-top centrifuge, Jouan SA, Saint-Herblain, France) to ensure the cell-free pipetting of a $100-\mu 1$ medium aliquot into wells of an additional plate, which was stored at $4{ }^{\circ} \mathrm{C}$ for later LDH determination. For LDH measurement, $100 \mu \mathrm{l}$ of reaction cocktail (Cytotoxicity Detection Kit, LDH; Roche) was added to each $100 \mu \mathrm{l}$ of medium and incubated for variable lengths of time to judge optimal incubation periods at $25^{\circ} \mathrm{C}$, and absorption was measured at $490 \mathrm{~nm}$ in a Bio-Tek (Winooski, VT) PowerWave ${ }^{\mathrm{TM}} \mathrm{XS}$ microplate reader, thereby using a $650 \mathrm{~nm}$ reference wavelength to account for optical interferences.

$L D H_{T O T}$. Immediately at the end of the experiment, to each well $50 \mu 1$ of $4 \%$ Triton X-100 was added for total cell lysis. To ensure adequate mixing, the plates were gently shaken at slow speed for 1 min (Vortex-Genie-2, Scientific Industries, Bohemia, NY). After centrifugation, 100- $\mu \mathrm{l}$ medium aliquots were taken for LDH measurement (see above).

\section{BrdU and WST-1 assays}

In a number of additional $\mathrm{Cu}$ application experiments (see Experiments), cells were assayed by LDH, BrdU, and WST-1 testing. WST-1 and BrdU kits were obtained from Roche Diagnostics. The WST-1 assay is a cell viability test, based on the cleavage of the tetrazolium salt WST-1 by mitochondrial dehydrogenases to form darkred formazan, which can be read at a wavelength of 440 $\mathrm{nm}$. The BrdU assay is a cell proliferation test, based on the incorporation of the pyrimidine analogue $\mathrm{BrdU}$ in place of thymidine into the DNA of proliferating cells. After denaturation of the DNA, anti-BrdU antibody peroxidase conjugate is bound to incorporated $\mathrm{BrdU}$, and assayed by adding tetramethylbenzidine substrate.

For BrdU, to $200 \mu \mathrm{l}$ of medium was added $20 \mu \mathrm{l}$ of BrdU-labeling solution, followed by incubation for $4 \mathrm{~h}$. Incubation was stopped by removing the media. FixDenat (Roche Diagnostics) (200 $\mu$ l per well) was added and incubated for $30 \mathrm{~min}$. After removal of the FixDenat solution, $100 \mu \mathrm{l}$ of anti-BrdU antibody peroxidase conjugate was added and incubated for $60 \mathrm{~min}$. After 
Table 1. Data on 490 nm Absorbance Signals in Minimum Essential Medium Eagle of Various Compositions

\begin{tabular}{lll}
\hline Medium processing & Composition $^{\mathrm{a}}$ & Absorbance $^{-}$ \\
\hline Not defoamed & $10 \% \mathrm{FBS}$, no PR & $0.193 \pm 0.036(19 \%)(n=6)$ \\
Not defoamed & $05 \% \mathrm{FBS}$, no PR & $0.080 \pm 0.009(12 \%)(n=6)$ \\
Defoamed & $10 \% \mathrm{FBS}$, no PR & $0.143 \pm 0.002(1 \%)(n=11)$ \\
Defoamed & $05 \% \mathrm{FBS}$, no PR & $0.075 \pm 0.005(7 \%)(n=6)$ \\
Defoamed & $05 \% \mathrm{FBS},+$ PR & $0.269 \pm 0.005(2 \%)(n=12)$ \\
\hline
\end{tabular}

See Materials and Methods for basic composition of the various Minimum Essential Medium Eagle media. Data are mean \pm $\mathrm{SD}$ (relative SD) (number of observations).

aFBS, fetal bovine serum; PR, phenol red.

removal, cells were washed three times in $200 \mu \mathrm{l}$ of washing solution; $100 \mu \mathrm{l}$ per well of TMB was added, and absorption was measured at $370 \mathrm{~nm}$ after 10,20, and $30 \mathrm{~min}$ of incubation. Eventually, data were further processed at optimal color development.

For WST-1, to $200 \mu \mathrm{l}$ of medium was added $20 \mu \mathrm{l}$ of WST-1 reagent, followed by shaking for $1 \mathrm{~min}$. Absorption was measured at $440 \mathrm{~nm}$ after incubation for 20, 40, and $60 \mathrm{~min}$. Eventually, data were further processed at optimal color development.

\section{Determination of cell size and number}

For determining cell sizes and numbers, at the end of the experiments, media were removed by pipetting. All wells were rinsed by adding $60 \mu \mathrm{l}$ of $\mathrm{Ca}-$ and $\mathrm{Mg}$-free phosphate-buffered saline (Sigma). After removal of the $\mathrm{Ca}$ - and $\mathrm{Mg}$-free phosphate-buffered saline, cells were dissociated in a $60-\mu 1$ mixture of $0.25 \%$ trypsin and $0.03 \%$ EDTA. After $10 \mathrm{~min}, 60 \mu \mathrm{l}$ of medium was added to terminate trypsin action. Cells were resuspended by gently pipetting the cell suspension to break up clumps. Cell suspensions were harvested into vials, the wells were rinsed with $60 \mu \mathrm{l}$ of $0.9 \% \mathrm{NaCl}$, and the rinsing solution was added to the vials. In vials, cell suspensions were diluted with $0.9 \% \mathrm{NaCl}$ to obtain optimized cell densities for Coulter counting (Coulter Multisizer II, Beckman Coulter, Fullerton, CA). Volumes actually used in Coulter counting were variable $(0.5-2 \mathrm{ml})$, depending on cell harvests and dilution factors.

The counter was calibrated in both Full and Narrow mode, using latex spheres $13.7 \mu \mathrm{m}$ in diameter (polystyrene divinyl benzene spherical polymer latex particles, Coulter Calibration Standard; Coulter Electronics Ltd.). Here, $K_{\mathrm{D}}$ is the calibration factor associated with each orifice tube diameter/length combination. The orifice tube used was $100 \mu \mathrm{m}$ in orifice diameter and $75 \mu \mathrm{m}$ in length. Counting was corrected for both dead time and coincidences, and performed in both Full and Narrow mode. The two modes were adopted in counting to obtain both the full-width spectra (in Offset at $7 \mu \mathrm{m}$ diameter) and a dedicated narrowed spectrum focused around the cell diameter ranges. In Narrow mode, counting was invariably corrected for diagonal cell passage through the orifice.

\section{Trypan blue estimation of cell viability}

The trypan blue staining method was used to estimate viability of cells taken into Coulter counting. At the end of the experiments, plates were centrifuged at $250 \mathrm{~g}$ for $10 \mathrm{~min}$, after which $5 \mu \mathrm{l}$ of $0.4 \%$ trypan blue (catalogue number 72-75-1, cell culture tested; Sigma) solution was added, after which the wells were gently shaken for 3 min. After 5 min of staining, the medium was transferred

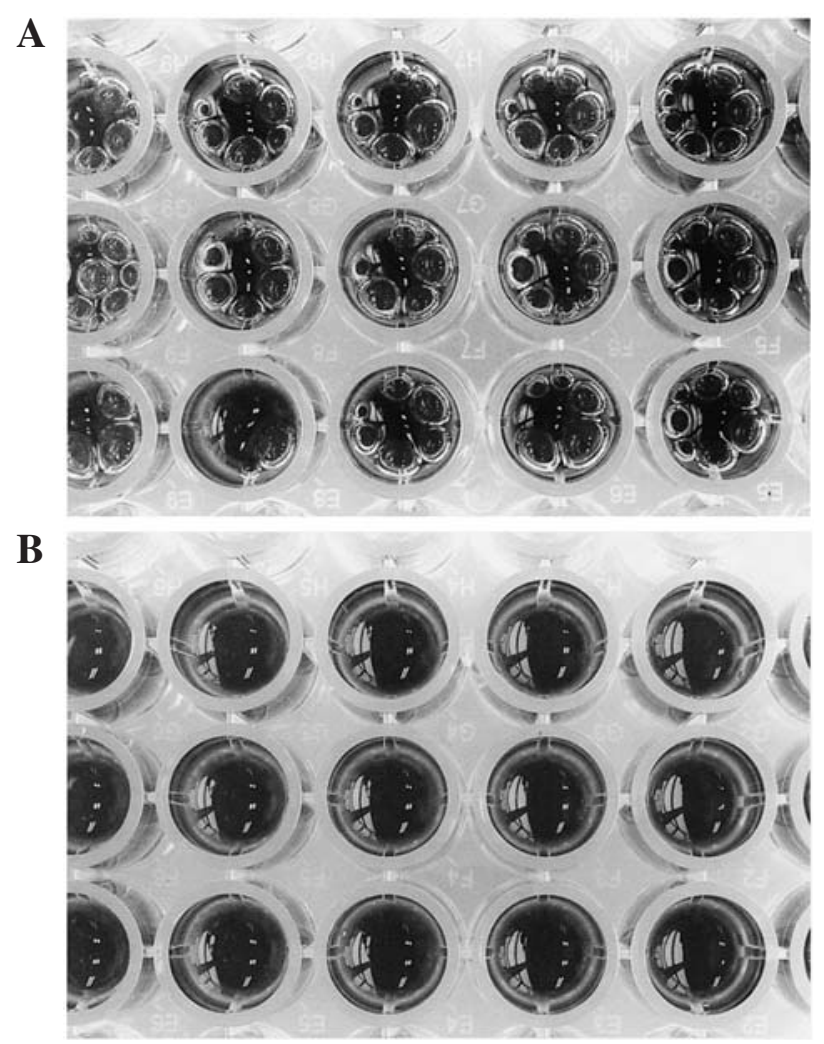

FIG. 1. Top view of microwells. (A) Without addition of silicon oil. (B) With addition of $5 \mu$ l of poly(dimethyl siloxane) oil (SF96-5, General Electric Silicones). Note the absence of any bubbles in the oil-treated wells. 


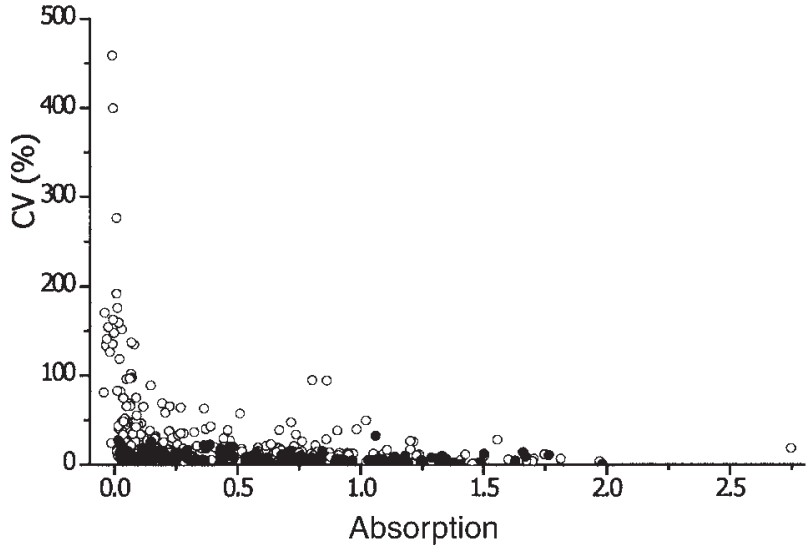

FIG. 2. Relative variance (coefficient of variation [CV], in $\%$ ) in $490 \mathrm{~nm}$ readings, at variable absorption levels, for nondefoamed $(\bigcirc, n=274)$ and defoamed $(\mathbf{O}, n=166)$ media.

into new wells, to see whether detached cells are dead or vital. To these wells, $50 \mu \mathrm{l}$ of $0.9 \% \mathrm{NaCl}$ was added to dilute the blue color, and to the wells containing the cells $30 \mu \mathrm{l}$ of $0.9 \% \mathrm{NaCl}$ was added. The numbers of bluecolored and total cells were counted with use of an inverted microscope (Olympus Tokyo CK, Tokyo, Japan), for both the attached cells and the detached cells in the trypan-blue colored medium.

\section{Defoaming}

To reduce errors in optical reading in LDH assays (LDH reaction mixture is "soap"-like), air bubbles were removed by adding $5 \mu \mathrm{l}$ of silicon oil to each well. The oil used was poly(dimethyl siloxane) (SF96-5, CAS number 63148-62-9, General Electric Silicones, Wilton, CT), with a density of $0.92 \mathrm{~g} / \mathrm{ml}$ and a viscosity of 5 centistokes. After the oil is added to the well and some air is gently blown over it, the oil spreads out as a thin film on the surface, thereby immediately removing all bubbles.

\section{Results and Discussion}

\section{Reducing background absorbance}

Media (not defoamed) were checked for $490 \mathrm{~nm}$ signal in both $5 \%$ and $10 \%$ FBS levels. Readings were $0.080 \pm 0.0094(\mathrm{SD} 12 \%, n=6)$ and $0.193 \pm 0.036(\mathrm{SD}$ $19 \%, n=6$ ) for $5 \%$ and $10 \%$ FBS, respectively (Table 1). In defoamed media (see below) readings for $10 \%$ FBS-containing medium were $0.143 \pm 0.0016$ (SD 1\%, $n=11)$. To check the phenol red contribution to the LDH $490 \mathrm{~nm}$ value, ${ }^{2}$ the dye (in an eventual $0.011 \mathrm{~g} / \mathrm{L}$ concentration) was added to $5 \%$ FBS-containing medium and compared with the $490 \mathrm{~nm}$ background reading in dyeless medium. Background readings (defoamed medium, see below) increased fourfold, from $0.075 \pm 0.005$ ( $n=$ 6 , dye-less) to $0.269 \pm 0.005$ ( $n=12$, phenol red added). Phenol red caused a fourfold increase in the $490 \mathrm{~nm}$ background reading (and a twofold background increase from $5 \%$ to $10 \%$ FBS), without, however, an appreciable increase in absolute background variance (Table 1). It should also be noted that phenol red slowly discolors from red to orange, which causes some variances at 490 $\mathrm{nm}$ (data not shown). All in all, taking three times the $490 \mathrm{~nm}$ signal background variance, sensitivity may be estimated as $3 \times 0.005=0.015$, which corresponds to a sensitivity (limit of detection) of about 500-600 cells per well. Based on the above, in all following experiments the media used contained 5\% FBS without phenol red.

\section{Defoaming}

In colorimetric assays of microplated media, reports stress the importance of avoiding spillage and foam formation in any step of the assay procedures ${ }^{2}$ : foam is reported to interfere with color measurement, and may thus cause serious errors in optical density reading. ${ }^{2,5}$ Haslam et al. ${ }^{2}$ suggested that foam bubbles may be disrupted by gently touching them with a tip of a sharpened lead pencil. In the experiments reported here, however, lead pencil testing showed that that approach is very time consuming and not fully effective: bubbles could not be removed totally in a reasonable time frame (data not shown). The approach adopted here was regarded as fully effective, more easy, less time consuming, more elegant, and more reproducible, and consisted of adding $5 \mu 1$ of a $0.92 \mathrm{~g} / \mathrm{ml}$ dense silicon oil to each well, which removed all bubbles after some air was gently blown over it after addition.

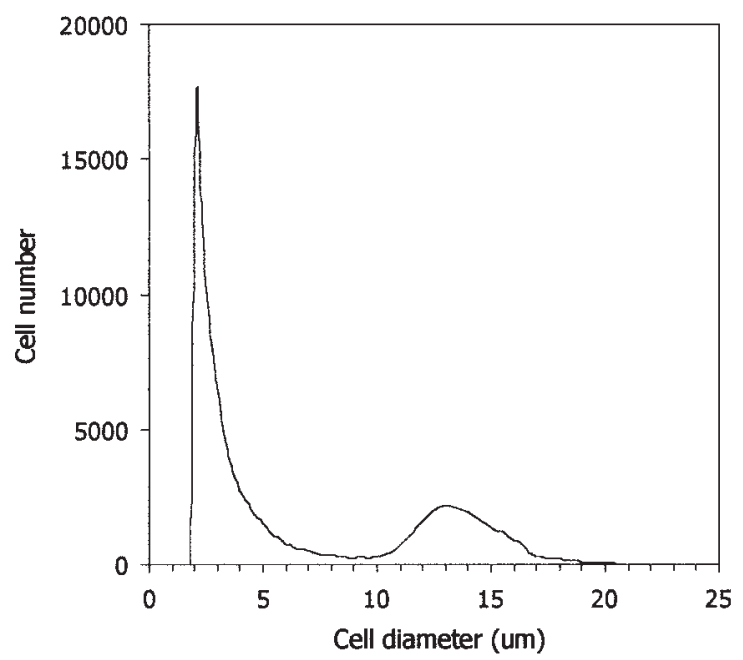

FIG. 3. Typical result from Coulter counting. The left-side fraction is attributable to debris; viable cells are indicated by the right-side fraction. 


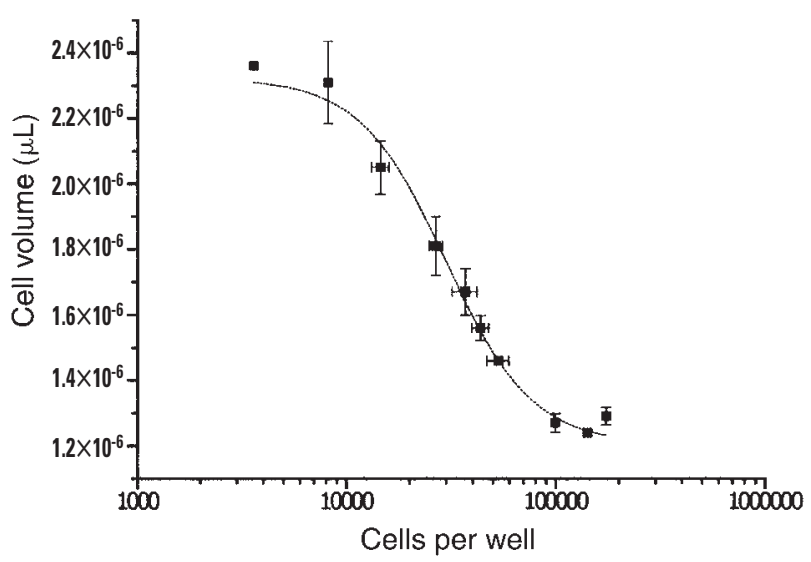

FIG. 4. Cell volume versus cell density. The data shown are averages; the vertical bars denote the SD values $(n=2)$.

The results are shown in both Fig. 1, which visualizes the complete absence of any bubbles after oil addition, and Fig. 2, which shows the relative variances in $490 \mathrm{~nm}$ readings at variable absorption levels for non-defoamed and defoamed media. The data roughly indicate that defoaming results in strongly reduced reading variances ranging from a factor of 2 at 1-3 units of absorption, up to a factor of 4-5 at $<1$ units of absorption. The latter results suggest reduced background reading with immediate consequences for signal sensitivity (see the reasoning in the preceding paragraph). The absorption scales used in the present experiments should be considered as generally relevant in many cell density classes (covering $\mathrm{LDH}_{\mathrm{TOT}}$ readings [0.45-1.3 units of absorption] and related LDH leakage [0.04-0.3 units of absorption]) in $2 \times$ $10^{4}-1 \times 10^{5}$ end-of-experiment cell densities (cells per well). ${ }^{6-16}$ It should be noted here that LDH signals related to LDH leakage are lower-range signals mostly; Fig.
2 thus indicates that especially the assessment of cell toxicity may be specifically improved by defoaming. The resulting 500 cells per well sensitivity in $490 \mathrm{~nm}$ LDH reading (see above) means that at an illustrative cell density of $10^{5}$ cells per well, cell death may be tracked down to $0.5 \%$. In tracking effects from defoaming, a Boltzman dose-response curve was fitted through a LDH curve set up by progressive increasing selenium concentrations in the applied medium (data not shown). The $50 \%$ effective concentration values were reproduced in a simulation experiment where observed data variances were stepwise increased and LDH signals were recalculated into a new data set by random selection within the variance width. The data indicate that any fractional increase in LDH uncertainty results in a comparable fractional increase in $50 \%$ effective concentration uncertainty. Based on the results above all further experimental readings were performed in defoamed media.

\section{Optimization of incubation time}

LDH reading depends on assay medium, cell type and density, reaction mixture concentration, and cocktail incubation time. In a series of preliminary experiments with defoamed 5\% FBS and phenol red-free medium, LDH reading was standardized by invariably adding $100 \mu 1$ of reaction cocktail to $100 \mu \mathrm{l}$ of medium. Incubation time was varied, however, from $30 \mathrm{~min}$ to $130 \mathrm{~min}$, and densities of the glioblastoma cells used in the present experiments ranged from 200 per well to $1.3 \times 10^{5}$ per well. Here, the range of densities was set by diluting the highest density suspension; results could thus be regarded as directly reflecting a similar dilution range in total LDH. The upper cell density was selected as representing a number of cells per well that would be some $20 \%$ higher than the threshold for a fully attached population. The re-

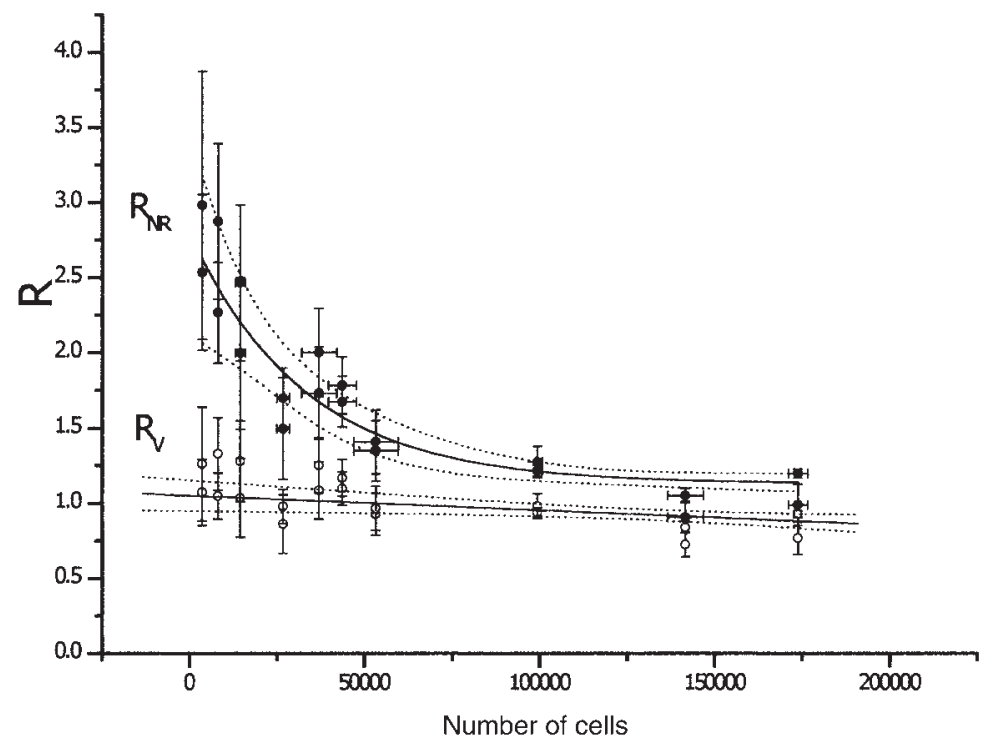

FIG. 5. The ratio $R$, expressed as $R_{\mathrm{NR}}$ and $R_{\mathrm{V}}$, both versus the cell density $C_{\mathrm{NR}} . R$ is calculated as the ratio between total lactate dehydrogenase $\left(\mathrm{LDH}_{\mathrm{TOT}}\right.$, expressed as cell density using the relative lactate dehydrogenase calibration curve) and the number of cells $C_{\mathrm{NR}}$ or the total cell volume $C_{\mathrm{V}} \cdot R_{\mathrm{NR}}=\mathrm{LDH}_{\mathrm{TOT}} / C_{\mathrm{NR}}(\mathbf{\bullet}), R_{\mathrm{V}}=\mathrm{LDH}_{\mathrm{TOT}} / C_{\mathrm{V}}$ (O), with $C_{\mathrm{V}}$ in pl to fit into a single-dimensioned $y$-axis. Vertical bars denote the SD values of $R$, for each $R$ value calculated from uncertainties in both lactate dehydrogenase signals $(n=3)$ and $C_{\mathrm{NR}}$ or $C_{\mathrm{V}}(n=2-4)$. 
A

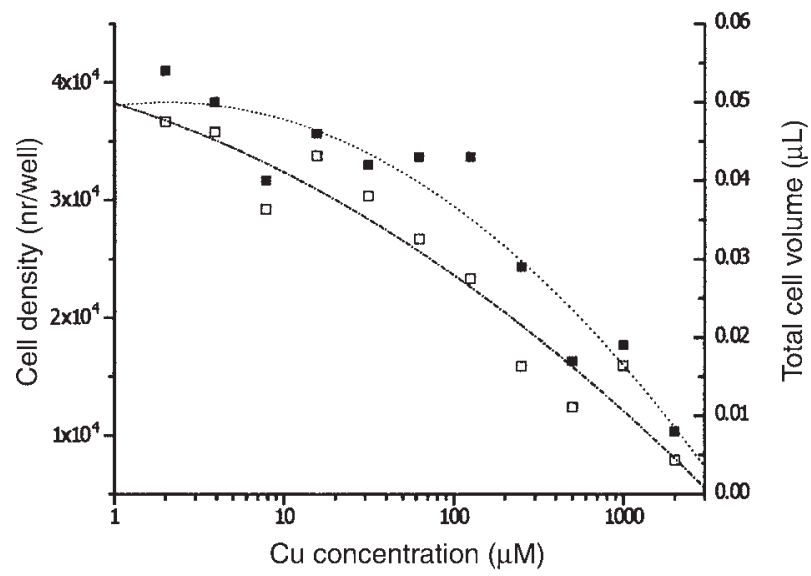

B

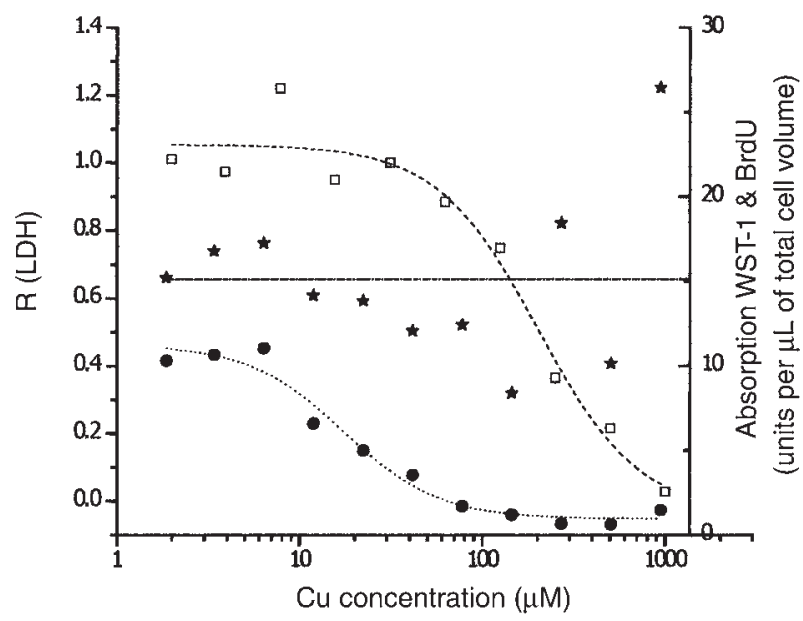

FIG. 6. (A) Cell density ( $\square$, cell number per well; left axis) and total cell volume ( $\boldsymbol{\square}$, in $\mu$ l per well; right axis) versus applied $\mathrm{Cu}$. (B) Ratio of lactate dehydrogenase ( $\mathrm{LDH})$ to total cell volume $\left(R_{\mathrm{V}}\right)(\square$, with volume in pl, see legend of Fig. 5; left axis) and absolute bromodeoxyuridine (BrdU) absorption per $\mu 1$ of total cell volume ( $\star$, right axis) and absolute sodium salt of 4-[4-(4-iodophenyl)-2-(4-nitrophenyl)-2H-5-tetrazolio]-1,3benzene disulfonate (WST-1) absorption per $\mu$ l of total cell volume (, right axis) versus applied $\mathrm{Cu}$.

sults (data not shown) indicated appreciable leveling off of the $490 \mathrm{~nm}$ signal at cell densities above $4 \times 10^{4}$ cells per well at incubation intervals above $60 \mathrm{~min}$. To maintain LDH signal at all densities, for all further experiments, incubation periods were set at $30 \mathrm{~min}$, and a relative LDH-signal calibration curve was set up to account for deviations from linearity (data not shown). Here, it is also interesting to note that Haslam et al., ${ }^{2}$ in their series of tests with a range of concentrations of purified rabbit LDH, found that although discussed as essentially proportional, absorbance at $490 \mathrm{~nm}$ signals showed a curved relationship with milliunits of LDH.

\section{Coulter counting: cell number and volume}

A Beckman Coulter counter was used to determine cell numbers and sizes. A typical result is shown in Fig. 3. The graph shows both cell densities and cell diameters, and clearly indicates two fractions. The left-side sharpedged fraction may be attributed to debris. ${ }^{17}$ In Coulter counting of lymphocytes, Winkelmeier et al. ${ }^{17}$ observed a further two-peaked cell fraction, which they assigned to the simultaneous presence of both vital and dead cells. However, Lucinani et al. ${ }^{18}$ in Coulter counting of HeLa cells, interpreted the two-peaked cell occurrences as reflecting the simultaneous presence of two cell populations of different mean cell diameter. The absence of dead cells in Coulter counting in the present experiments (Fig. 3) was screened by straightforward trypan blue testing; hardly any coloring could be observed in attached cells, and rinsing removed all detached non-vital/dead cells before Coulter counting (data not shown). As a result, the data in Fig. 3 were interpreted in the present study as showing vital cells only.

In a series of experiments, cells were seeded and harvested at varying end-point densities. All samples were Coulter-counted, and the results are shown in Fig. 4. The data indicate a clear decrease in cell volume with increasing end-point cell density. Haslam et al. ${ }^{2}$ found relationships between doubling time and mean cell diameter in a series of various cell types, but the work of Luciani et al., ${ }^{18}$ with HeLa cells, should also be notedthey showed cell volume decreases as a function of time after seeding under maintained exponential growth. HeLa cells do not undergo defined density-dependent growth arrest, but, in the reported two-peaked population, apparently show a shift towards the cells with the smallest volumes, as apart from a general shrinking in volume with increasing density. ${ }^{18}$ In the present paper, volume decreases were not observed without changes in doubling time, but were without any clear (two-peaked) presence of different cell populations (Fig. 3); the data may thus be attributed to general shrinking at increasing density, but should serve in more detailed interpretation of LDH data in cells of different density.

\section{LDH signal: cell number or volume?}

For more detailed interpretation of LDH signals in experiments with growing cells of varying density, a series of further measurements was performed in 5\% FBS-containing, phenol red-free, defoamed medium, with 30-min cocktail incubations, with corrections applied for deviations from LDH-signal linearity, and with all LDH data compared with simultaneously gathered Coulter counter data. In comparisons, $\mathrm{LDH}_{\mathrm{TOT}}$ was taken into account only, and $\mathrm{LDH}_{\text {Tот }}$ was considered relative to both cell total volume and cell numbers. In all cases, a ratio $R$ was calculated, either as $R_{\mathrm{V}}=\mathrm{LDH}_{\mathrm{TOT}} /$ cell total volume or 
as $R_{\mathrm{NR}}=\mathrm{LDH}_{\mathrm{TOT}} /$ cell numbers. Figure 5 gives both $R_{\mathrm{V}}$ and $R_{\mathrm{NR}}$ data, versus the counted cell numbers. The results clearly show $R_{\mathrm{V}}$ as a constant, with $R_{\mathrm{NR}}$ continuously decreasing with increasing cell density. This result suggests that $\mathrm{LDH}_{\text {TOT }}$ should be regarded as reflecting cell total volume rather than cell numbers: LDH shows up as a constant per unit of cell volume, and the decrease in $R_{\mathrm{NR}}$ with increasing cell density reflects the progressive decrease in volume per cell (see also Fig. 4).

The constant $R_{\mathrm{V}}$ for $\mathrm{LDH}_{\mathrm{TOT}}$ observed in the present study requires some reflection on cells, densities, and volumes; although different cell types may contain different amounts of LDH ( $R_{\mathrm{V}}$ may thus be cell type specific), Haslam et al. ${ }^{2}$ reported that $R_{\mathrm{V}}$ was the same within a factor of 2 for seven different cell lines tested under varying doubling times. Cell LDH content may also be affected by changes in culture state during incubation; $\mathrm{LDH}_{\mathrm{TOT}}$ per cell is reported to relate to (controlled) batch-medium glucose level. ${ }^{19}$ The reasoning of Kurokawa et al. ${ }^{19}$ was that high $\mathrm{LDH}_{\text {TOT }}$ per cell is correlated to high cell glucose consumption so that glucose overflow (due to high glucose supply) may be minimized by keeping cell glucose concentrations low. It should be noted here, however, that both glucose consumption and $\mathrm{LDH}_{\mathrm{TOT}}$ were reported exclusively on a per cell basis, but their data also showed higher $\mathrm{LDH}_{\text {TOт }}$ per cell with lower cell densities. ${ }^{19}$ Possibly, as with LDH (Fig. 5), glucose consumption should have been expressed in terms of cell volume rather than cell numbers; as also reasoned by Winkelmeier et al., ${ }^{17}$ cellular responses may be visualized by cell volume in addition to, rather than only by, numbers or proliferation.

\section{LDH, WST-1, and BrdU assays in \\ $\mathrm{Cu}$ exposure experiments}

Figure 6 presents data on the LDH, WST-1, and BrdU tests in $\mathrm{Cu}$ exposure experiments. Figure 6A shows that both cell density and total cell volume decrease with increasing $\mathrm{Cu}$ concentration; the averaged volume per cell increases up to added $\mathrm{Cu}$ of $100 \mu \mathrm{mol} / \mathrm{L}$, and decreases from then onwards (data not shown). Figure 6B clearly indicates that LDH and WST-1, both being cell viability markers and both expressed as signal per unit of cell volume, decrease with increasing $\mathrm{Cu}$ supply, with WST-1 dropping earlier in the $\mathrm{Cu}$ range than $\mathrm{LDH}$. BrdU, on the other hand, expressed as signal per unit of cell volume, remains relatively stable over the whole administered $\mathrm{Cu}$ range (Fig. 6B; comparable outcomes on basis of BrdU signal per cell, data not shown). The results, especially when compared to the data from Fig. 5, clearly indicate where cell LDH $\left(R_{\mathrm{V}}\right)$ does not drop by mere changes in cell density, it does so by $\mathrm{Cu}$ physiological action. Figure $6 \mathrm{~B}$ suggests that, in the present $\mathrm{Cu}$ series, cell viability may be affected (LDH, WST-1) without visible or significant changes in cell proliferation (BrdU). Overall, data in Figs. 5 and 6 suggest that LDH should be expressed on a per cell volume basis rather than per cell, to avoid that mere density effects (changes in cell volumes) contribute to signals on compound or metal toxicity.

\section{References}

1. Riss TL, Moravec RA: Use of multiple assay endpoints to investigate the effects of incubation time, dose of toxin, and plating density in cell-based cytotoxicity assays. Assay Drug Dev Technol 2004;2:51-62.

2. Haslam G, Wyatt D, Kitos PA: Estimating the number of viable animal cells in multi-well cultures based on their lactate dehydrogenase activities. Cytotechnology 2000;32: 63-75.

3. Chiba K, Kawakami K, Tohyama K: Simultaneous evaluation of cell viability by neutral red, MTT and crystal violet staining assays of the same cells. Toxicol In Vitro 1998;12:251-258.

4. Goergen JL, Marc A, Engasser JM: Determination of cell lysis and death kinetics in continuous hybridoma cultures from the measurement of lactate dehydrogenase release. Cytotechnology 1993;11:189-195.

5. Martin A, Clynes M: Comparison of 5 microplate colorimetric assays for in vitro cytotoxicity testing and cell proliferation assays. Cytotechnology 1993;11:49-58.

6. Magwood S, George S: In vitro alternatives to whole animal testing. Comparative cytotoxicity studies of divalent metals in established cell lines derived from tropical and temperate water fish species in a neutral red assay. Mar Environ Res 1996;42:1-4.

7. Virág L, Kerékgyártó C, Fachet J: A simple, rapid and sensitive fluorimetric assay for the measurement of cell-mediated cytotoxicity. J Immunol Methods 1995;185:199-208.

8. Hellweg CE, Baumstark-Khan C, Horneck G: Enhanced green fluorescent protein as reporter protein for biomonitoring of cytotoxic effects in mammalian cells. Anal Chim Acta 2001;427:191-199.

9. Martin A, Clynes M: Acid phosphatase: endpoint for in vitro toxicity tests. In Vitro Cell Dev Biol 1991;27A:183-184.

10. Seth R, Yang S, Choi S, Sabean M, Roberts EA: In vitro assessment of copper-induced toxicity in the human hepatoma line, Hep G2. Toxicol In Vitro 2004;18:501-509.

11. Tuschl H, Schwab CE: Flow cytometric methods used as screening tests for basal toxicity of chemicals. Toxicol In Vitro 2004;18:483-491.

12. Shoji R, Sakai Y, Sakoda A, Suzuki M: Preservation of microplate-attached human hepatoma cells and their use in cytotoxicity tests. Cytotechnology 2000;32:147-155.

13. Plewa MJ, Kargalioglu Y, Vankerk D, Minear RA, Wagner ED: Development of quantitative comparative cytotoxicity and genotoxicity assays for environmental hazardous chemicals. Water Sci Technol 2000;42:109-116.

14. Dent MF, Hubbold L, Radford H, Wilson AP: The methylene blue colorimetric microassay for determining cell line response to growth factors. Cytotechnology 1995;17:27-33.

15. Shoji R, Sakoda A, Sakai Y, Utsumi H, Suzuki M: A new assay for evaluating hepatotoxicity and cytotoxicity using LDL-uptake activity of liver cells. $J$ Health Sci 2000;46: 493-502.

16. Bedard J, May S, Barbeau D, Yuen L, Rando RF, Bowlin TL: A high throughput colorimetric cell proliferation assay for the identification of human cytomegalovirus inhibitors. Antiviral Res 1999;41:35-43. 
17. Winkelmeier P, Glauner B, Lindl T: Quantification of cytotoxicity by cell volume and cell proliferation. Altern Lab Anim 1993;21:269-280.

18. Lucinani AM, Rosi A, Matarrese P, Arancia G, Guidoni L, Viti V: Changes in cell volume and internal sodium concentration in HeLa cells during exponential growth and following lonidamine treatment. Eur J Cell Biol 2001;80: 187-195.

19. Kurokawa H, Park YS, Lijima S, Kobayashi T: Growth characteristics in fed-batch culture of hybridoma cells with control of glucose and glutamine concentrations. Biotechnol Bioeng 1994;44:95-103.
Address reprint requests to: Hubert Th. Wolterbeek, Ph.D. Department of Radiation, Radionuclides, and Reactors

Faculty of Applied Sciences University of Technology Delft Mekelweg 15

2629 JB Delft, The Netherlands

E-mail: H.T.Wolterbeek@tnw.tudelft.nl 